\title{
A LEITURA POLÍTICA DA PALAVRA: UMA EXPERIÊNCIA DIDÁTICA, TEÓRICA E TAMBÉM POLÍTICA
}

\author{
THE POLITICAL READING OF THE WORD: A TEACHING, THEORETICAL AND ALSO POLITICAL \\ EXPERIENCE
}

\author{
Helson Flávio da Silva Sobrinho' \\ ${ }^{1}$ Universidade Federal de Alagoas (UFAL), Maceió, AL, Brasil \\ helsonf@gmail.com
}

Recebido em 25 nov. 2019

Aceito em 15 dez.2019

\begin{abstract}
Resumo: Este artigo possui dois objetivos que estão essencialmente articulados, quais sejam: apresentar resultados de uma atividade didática de leitura-interpretação produzida em uma universidade eque foi estendida pelos/as alunos/as aoutros grupos de sujeitos fora do espaço universitário; e refletir teórica e politicamente sobre essa experiência/vivência educativa enquanto gesto político de ensino. O texto está dividido em duas partes: primeiramente, traçaremos questões de ordem teórica e metodológica na Análise de Discurso (AD) de filiação pecheutiana quanto à produção histórica de sentidos, sobretudo, nas práticas educativas. Já na segunda parte seguiremos com o relato e a reflexão crítica sobre a vivência da atividade didática em seus gestos de interpretação que possibilitaram o questionamento da produção de sentidos por meio da análise da palavra "política",a partir de sua articulação com as condições históricas de produção. O que orientou nossa experiência/vivência didática e educativa foram os objetivos de buscar possibilidades de questionar os efeitos de sentido em sua historicidade, produzir e divulgar conhecimento, possibilitar aos/as alunos/as gestos capazes de reconhecer/identificar as filiações históricas de sentidos e compreender a realidade política brasileira. Esperamos que o/a leitor/a possa nos acompanhar nesta reflexão, tomar posição crítica e, até mesmo, buscar outros lugares possíveis para ressignificar as práticas educativas e seus gestos políticos de intepretação.
\end{abstract}

Palavras-chave: Discurso.Gesto de interpretação.Política.Educação.

Abstract: This article has two aims that are essentially articulated, namely: to present results of a didactic reading-interpretation activity produced in a university and that was extended by the students to other groups of subjects outside the university space; and reflect theoretically and politically on this educational experience as a political act of teaching. Thus, the text is divided into two parts: first, we will outline theoretical and methodological questions in the Discourse Analysis (AD) of pecheutian affiliation regarding the historical production of meanings, especially in educational practices. And in the second part, we will continue with the report and the critical reflection on the experience of didactic activity in its interpretive acts that allowed the questioning of the production of meanings through the analysis of the word "politics" from its articulation with historical conditions of production. What guides our didactic and educational experience were the objectives of searching for possibilities of effects on its historicity, production and dissemination of knowledge, the possibility of/as students gestures able to recognize/identify historical affiliations of meanings and understand reality Brazilian politics. In the same way, we hope that the reader be able to follow us in this reflection, take a critical position and even look for other possible places to redefine educational practices and their political gestures of interpretation.

Keywords: Discourse.Gestures of interpretation.Politics. Education. 


\section{GESTOS DE INTERPRETAÇÃO NA ANÁLISE DO DISCURSO (AD): FILIAÇÕES TEÓRICAS, POLÍTICAS E IDEOLÓGICAS}

A teoria é política. $E$ a análise de discurso que se filia à $M$. Pêcheux 'sabe' disso. (ORLANDI, 2001, p. 36)

As línguas naturais são capazes de política. (PÊCHEUX, 2004, p. 24)

Para iniciar esta reflexão, é necessário demarcar nossa filiação teórica, política e também ideológica. Cabe ressaltar que dizemos teórica, política e ideológica porque estamos situados na posição científica e política da Análise do Discurso (AD), na linha de seu fundador, Michel Pêcheux, ou seja, estamos inscritos na teoria materialista dos processos discursivos. Dizer isso tem implicações fortes nos modos de escrita, leitura e interpretação do presente artigo, massobretudo revela que, da posição teórica e política da $A D$, podemos compreender que se faz ciência e política ao mesmo tempo. Como diz Pêcheux (1997), não há discurso científicolivre de ideologias, e, sobretudo, nenhuma prática científica é desinteressada ${ }^{1}$.

Assim, não só o discurso, mas o nosso fazer enquanto analistasé efeitoe trabalho ${ }^{2}$ nas atividades que desenvolvemos no cotidiano e nas relações institucionais. A nosso ver, a gênese detoda prática está nas relações sociais de uma determinada sociedade, ou seja, nossa prática, enquanto sujeitos, é essencialmente histórica. Devemos levar isso em consideração para realizarmos uma atividade didática, científica, filosófica, política, responsável e, sobretudo,crítica e consequente.

Avancemosnas questões. O nosso objeto de pesquisa é o discurso, ou seja, os efeitos de sentidos produzidos entre os sujeitos interlocutores em determinadas condições materiais, ideológicas ehistóricas de produção. Trata-se de um objeto sócio-histórico e, por isso, essencialmente político, já que o discurso é a práxis de

\footnotetext{
${ }^{1}$ Segundo Pêcheux, "a história da produção de conhecimentos não está acima ou separada da história da luta de classes, como o 'bom lado' da história se oporia ao 'mau lado'; essa história está inscrita, com sua especificidade, na história da luta de classes" (1997, p. 190). Ainda Pêcheux: "é absolutamente impossível encontrar um puro 'discurso científico' sem ligação com alguma ideologia" (1997, p. 198).

${ }^{2}$ Atentamos para o que diz Pêcheux (2002, p. 56): "todo discurso é o índice potencial de uma agitação nas filiações sócio-históricas de identificação, na medida em que ele constitui ao mesmo tempo umefeitodessas filiações e um trabalho[...] de deslocamento no seu espaço".
} 
sujeitos nas relações históricas de reprodução e transformação de uma sociedade. Como diz Henry (1997, p. 24), fundamentado em Pêcheux, "o instrumento da prática política é o discurso, ou mais precisamente, que a prática política tem como função, pelo discurso, transformar as relações sociais reformulando a demanda social".

Assim, da posição da Análise do Discurso, produzimos conhecimento sobre o discurso (efeitos de sentidos) e sobre os sujeitos (nas tomadas de posições ideológicas) em condições determinadas de produção. Portanto, os efeitos de sentido são produzidos em sua historicidade, na relação da língua (sistema significante capaz de falhas) com a história (práxis material), bem como na relação do sujeito com a ideologia e o inconsciente.

Como foi dito, o discurso é práxis sócio-histórica; é levando isso em consideração que desenvolvemos análises de diversos discursos que circulam na formação social na qual estamos situados, no caso em estudo, na sociedade capitalista, mais especificamente, na formação social brasileiracom suas raízes escravocrata, elitista, patriarcal e autoritária.

Em síntese, nossas práticas teóricas e políticas nos fazem entender que, compreendendo o funcionamento do discurso, também compreendemos o fazer histórico dos sujeitos em determinada formação social. Ao produzir esse gesto de análise,entendemos, portanto, o funcionamento da sociedade capitalista em sua discursividade nas relações de reprodução/transformação das condições materiais e ideológicas de produção.

A Análise do Discurso é uma disciplina de interpretação (PÊCHEUX, 2002), uma disciplina de entremeio (ORLANDI, 1996), que trabalha na contradição entre a Linguística, o Materialismo Histórico e a Psicanálise. Nem a língua, nem o sujeito, nem a história são transparentes (ORLANDI,1999, p. 19-20).Deve-se destacar que há uma determinação histórica dos sentidos e dos sujeitos, e que tanto os sujeitos como os sentidos estão sempre em movimento dinâmico e contraditório nas relações sócio-históricas.

No presente estudo, trata-se de compreender o discurso e seus efeitos de sentidos entre os interlocutores na concretude de sua processualidade históricomaterial e ideológica. Nessa direção, é importante ressaltar que a AD tem capacidade tanto teórica como metodológica para compreender a produção de 
sentidos e as implicações de tais efeitos em seu caráter político no devir histórico dos sujeitos em sociedade.

Quando dizemos isso, estamos falando também dos gestos de interpretação (ORLANDI, 1996) dos sujeitos sobre o real da história. O gesto de interpretação tem a ver com a relação língua-sujeito-ideologia numa conjuntura dada. $\mathrm{O}$ gesto de interpretação é sempre uma tomada de posição diante das questões que circunscrevem nossas práticas históricas. O sujeito, como diz Orlandi (1996), é condenado a interpretar; por outro lado, a história exige interpretação eexigeque atribuamos sentidos e a signifiquemos. É um eterno dar sentido às nossas práticas, e, enquanto sujeitos, somos significados e ressignificados na processualidade histórica. Ao atribuir sentido ao mundo o sujeito também se significa na práxis social de uma conjuntura dada.

É preciso destacar, ainda, que o sentido,tendo uma direção política, também tem direções ideológicas e implicações sobre o real sócio-histórico. Não se interpreta sem se inscrever na língua, nemdespido da ideologia, muito menos fora das relações históricas. Não se interpreta de um modo qualquer, nem com o uso de quaisquer palavras. Como sabemos, a ideologia constitui os sujeitos e suas formas de ser nas sociedades ${ }^{3}$. Assim, a interpretação é um gesto sobre o real; uma vez que significa o real, significa também o sujeito e intervém no mundo sob determinadas condições sócio-históricas. Como diz Orlandi (1998, p. 22), "um gesto de interpretação é uma intervenção no real do sentido. Daí o peso e a importância do interpretar".

Como estamos falando de gesto de interpretação na perspectiva da Análise do Discursocomo uma tomada de posição política, é preciso dizer também que, no presenteartigo, buscamos inscrever-nos nas filiações históricas de sentidos e posição-sujeito da classe trabalhadora, porquanto segundo Pêcheux:

Não podemos pretender falar de discurso político sem tomar simultaneamente posição na luta de classes, já que essa tomada de posição determina, na verdade, a maneira de conceber as formas materiais concretas sob as quais as "ideias" entram em luta na história. (PÊCHEUX, 2011a, p. 178).

\footnotetext{
${ }^{3}$ Pêcheux (1997, p. 133 e 149), fundamentado criticamente em Althusser, compreende que "a ideologia interpela os indivíduos em sujeitos". E acrescenta: "só há prática através de e sob uma ideologia" e "só há ideologia pelo sujeito e para os sujeitos".
} 
Filiamo-nos à ideologia contra-hegemônica que reivindica uma sociedade justa e igualitária. Como sabemos, na sociedade capitalista existem duas classes fundamentais (capitalistas e trabalhadores),cujas relações são antagônicas e os interesses, inconciliáveis, visto que as relações sociais burguesas se dão enquanto relações de exploração de uma classe sobre a outra. Cabe destacar também que as lutas e os conflitos que derivam dessas relações de exploração fazem mover a história dos sujeitos e dos sentidos.

Nossa posição e nosso gesto de interpretação sobre o realse dão na perspectiva da classe trabalhadora, a fim de produzir resistências e lutar por formas de sociabilidade emancipadoras.A nosso ver, "a perspectiva teórico-política burguesa impede a compreensão da totalidade social concreta, pois não visa à crítica ao capitalismo, neutralizando por vezes a práxis revolucionária." (SILVA SOBRINHO, 2014, p. 41). Nessa direção, nossas filiações teóricas são também filiações político-ideológicas. Quanto a isso, não há problema, pois, como foi dito na epígrafe, a teoria é política.

Assumir (tomar) posição na prática científica é hoje cada vez mais importante, já quenos deparamos com posições-sujeito que dizem ser possível fazer ciência e também desenvolver práticas escolares (pedagógicas, didáticas, educativas) sem a tomada de partido ou a tomada de posição diante dos conflitos sociais. A nosso ver, essa defesa da "escola sem partido" e de que a ciência é "neutra" é uma manifestação das práticas ideológicas da classe dominante que quer frear as resistências para manter os privilégios, reproduzir a (des)ordem da exploração capitalista sem que os sujeitos produzam algumquestionamento ou crítica. Como diz Freire (1996):

Creio que nunca precisou o professor progressista estar tão advertido quanto hoje em face da esperteza com que a ideologia dominante insinua a neutralidade da educação. Desse ponto de vista, que é reacionário, o espaço pedagógico, neutro por excelência, é aquele em que se treinam os alunos para práticas apolíticas, como se a maneira humana de estar no mundo fosse ou pudesse ser uma maneira neutra. (FREIRE, 1996, p. 98)

Por tudo isso, é preciso dizer que na perspectiva teórico-política a que nos filiamos não podemos nos deixar seduzir pelo efeito ideológico de transparência da linguagem/discurso, nem conceber que a ciência tem atividade "neutra", e muito menos que a educação pode existir "sem tomar partido". Em todas as instâncias da vida humana em sociedade, há sempre a presença contraditória das ideologias 
(forças materiais em lutas) em nossas práticas. Por isso, problematizamos as relações dos sujeitos com os sentidos nas práticas educativas e históricas de interpretação na formação social capitalista brasileira. Dar sentido é sempre um gesto de interpretação, é sempre uma tomada de posição política e ideológica e tem implicações no real da história.

\section{EDUCAÇÃO, VIVÊNCIA DIDÁTICA E PRÁTICA POLÍTICA: OS DISCURSOS (IM)POSSÍVEIS}

Ensinar não é transferirconhecimento, mas criar as possibilidades para a sua produção ou a sua construção. (FREIRE, 1996, p. 22)

[...] são precisamente os homens que transformam as circunstâncias e que o próprio educador precisa ser educado. (MARX, 1998, p. 100).

Em nossas pesquisas sobre educação e discurso, temos levado em consideração que a educação é, sobretudo, uma prática política. Trata-sede uma forma de nos posicionarmos no mundo e de enfrentar os desafios da vida numa sociedade desigual. Compreender a educação como uma prática política é também uma forma de articular as práticas educativas com o fazer do analista de discurso. Nessa direção, filiamo-nos às reflexões de Paulo Freire (1996) e IstvánMészáros (2005), pois esses autores concebem o processo educativo em seu caráter contraditório (dialético) de reprodução e transformação de relações materiais e ideológicas de produção.

Como bem dizem Freire (1996) e Mészáros (2005):

[...] como experiência especificamente humana, a educação é uma forma de intervenção no mundo. Intervenção que além do conhecimento dos conteúdos bem ou mal ensinados e/ou aprendidos implica tanto o esforço de reprodução da ideologia dominante quanto o seu desmascaramento. Dialética e contraditória, não poderia ser a educação só uma ou só a outra dessas coisas. Nem apenas reprodutora nem apenas desmascaradora da ideologia dominante. (FREIRE, 1996, p. 98).

[...] o papel da educação é soberano, tanto para a elaboração de estratégias apropriadas e adequadas para mudar as condições objetivas de reprodução, como para a automudança consciente dos indivíduos chamados a concretizar a criação de uma ordem social metabólica radicalmente diferente. (MÉSZÁROS, 2005, p. 65). 
O que nos ensinam Freire (1996) e Mészáros (2005) é que a educação é um processo essencialmente humano e histórico e que o processo educativo está relacionado à totalidade dos processos sociais, ou seja, é parte das práticas de reprodução e transformação dos sujeitos em sociedade. Podemos dizer, ainda, que as práticas educativas têm intrínseca relação com a atividade de trabalho que é abase de toda formação social. Assim, compreendemos o trabalho como a relação que os sujeitos estabelecem com a natureza para a sua subsistência e reprodução social. Vale ressaltar que a concepção de trabalho aqui adotada deriva da perspectiva marxiana:o trabalho é fundante do ser social. O sujeito transforma a natureza e se transforma através do trabalho e é dessa atividade de onde deriva o conhecimento que precisa ser repassado para as novas geraçõespelo complexo social da educação.

O complexo da educação contribui para a reprodução social dos sujeitos e dos sentidos em seus modos de ser e fazer; ele faz parte da reprodução/transformação de uma sociedade e, por isso, também está articulado ao complexo do trabalho. No entanto, a sociedade capitalista, com a lógica do lucro, baseada na propriedade privada e no individualismo burguês, faz o trabalho se apresentar de modo estranhado/alienado e isso tem efeitos cruciais sobre as práticas educativas ${ }^{4}$.

Nessa perspectiva, que leva em consideração a lógica do capital que torna tudo mercadoria - inclusive a educação - a escola, enquanto uma instituição ideológica que desenvolve certa prática de leitura do político e da política,é também responsável por formar os sujeitos para o exercício de determinadas funções nas relações sociais capitalistas. Essas relações sociaiscunhadas pela lógica do capital (exploração do trabalho) são, pelo efeito da ideologia dominante, postas como "naturais" e "eternas". Por isso, as modalidades de ensino, as disciplinas, os conteúdos curriculares e a própria instituição escolar estão implicadas na forma de ser da sociedade burguesa.

Os interesses de classes, mais precisamente da classe que detém o poder material (econômico), prevalecem nos direcionamentos das práticas e políticas

\footnotetext{
${ }^{4}$ De fato, entendemos trabalho no sentido ontológico como fundante do ser social. Ver Marx (1985) e Lukács (2013). Trata-se da relação que os sujeitos estabelecem com a natureza para a produção de coisas úteis a sua existência material e espiritual. No entanto, consideramos também a existência do trabalho alienado/estranhado (assalariado) na sociedade capitalista, na qual a lógica da mercadoria é dominante sobre o valor de uso, e a produção dos objetos (mercadoria) se dá pela determinação do lucro e da propriedade privada.
} 
educacionais na ordem reprodutiva desta sociedade. Para compreender essa imbricação contraditória, basta o/a leitor/a analisar as reformas praticadas na educação pelos últimos governos, pois sempre há direcionamentos políticos e ideológicos, mesmo não reconhecidos ou ditos como tais.

Apesar de entender que a educação na sociedade capitalista também se torna uma mercadoria e que o/a professor/a faz parte da classe trabalhadora e sofre os efeitos da exploração e alienação do trabalho, a prática docente não deve se reduzir a essa lógica desumanizante. A nosso ver, numa perspectiva ontológica,a atividade docente diz respeito à formação humana, não se trata de "treinamento", mas de experiência e vivência teórico-prática, de gestos políticos, modos de estar e atuar no mundo que têm possibilidade transformadora. É nesse sentido que Freire (1996) afirma que "ensinar não é transferir conhecimento, mas criar as possibilidades para a sua produção ou a sua construção" (FREIRE, 1996, p. 22).

Buscar possibilidades de questionar os efeitos de sentido em sua historicidade, produzir e divulgar conhecimento, possibilitar aos/as alunos/as gestos capazes de reconhecer/identificar as filiações históricas de sentidos e compreender a realidade política brasileira no desejo de dar passos para um outro mundo possível: issoorientou nossa experiência/vivência didática. Apesar de ser a lógica do capital irreformável/incorrigível, como nos diz Mészáros (2005), sabemos que as práticas educativas podem contribuir para lançar um novo horizonte social, possibilitando que os sujeitem busquem pensar e agir criticamente, na tentativa de romper, em certa medida, com os efeitos alienantes do ensino como uma prática "neutra" diante do político.

Seguiremos agora com o relato de nossa experiência/vivência didática na universidade e sua extensão realizada pelos/as alunos/as fora da universidade. Essa atividade se deu do seguinte modo: ao vivenciar as condições de produção de um período bastante conturbado de eleições municipais, propusemos aos estudantes da graduação em Letras uma atividade que pretendia pensar, numa perspectiva discursiva, a palavra "política" e suas diferentes discursividades, marcadas pelos processos ideológicos. Tarefa difícil para o momento, pois havia condições determinadas de produção de sentidos sobre a política.

No contexto histórico dessa experiência/vivência educativa nos deparávamos com dizeres que se cruzavam com sentidos de completa negação e ojeriza. 
Confrontávamo-nos com enunciados do tipo: "sou apolítico", "sou antipolítico", ou ainda, "detesto política". Mas também nos deparávamos com outros dizeres que demonstravam o desejo de compreender que não há como se esquivar da política: "temos de lutar por um Brasil melhor", "se eu não decidir, os outros vão decidir por mim", e também, "somos sujeitos políticos" 5 .

Desse modo, sendo sujeitos políticos e sujeitos à interpretação, somos,sobretudo,sujeitos históricos. Isso tudo atravessa e marca o funcionamento da língua, produzefeitos de sentidos os mais diversos. Daí buscarmos uma tentativa crítica de refletir sobre a palavra "política" e questionarseus sentidos dominantes e seus efeitos de transparência da linguagem.Queríamos interrogar os sentidos, problematizar os gestos de interpretação, quebrar as evidências ideológicas.

Naquele momento, estávamos estudando em sala de aula a produção de sentidos em dicionários. Tomávamos os dicionários como saber histórico e objeto discursivo. Nessa direção, a turma começou a questionar a suposta estabilidade da significação das palavras, abrindo um leque de interpretação.

Entendendo o dicionário como um instrumento de gramatização $^{6}$, questionamos como os sentidos se davam e como pareciam tercerta estabilização (provisória) no social. Compreendemos que tal estabilização e, de modo contraditório, suas (im)possíveisderivas de sentidos, estavam ligadas às condições de produção de uma determinada sociedade. Dizemos (im)possíveis porque consideramos que o sentido, possuindo caráter contraditório, pode ser sempre outro, como ensinam Orlandi (1996) e Pêcheux (2002) ${ }^{7}$.

Estávamos, pois, diante da prática da AD: articular o dizer e suas condições de produção materiais e ideológicas. Dessas primeiras reflexões teóricas fizemos uma

\footnotetext{
5 Embora seja necessária uma análise mais aprofundada do enunciado que segue, arriscamos dizer com Aristóteles (2004, p. 14) que "o homem é um animal político". E podemos acrescentar com Marx (1996, p. 26) que "o homem é, no sentido mais literal, um zoonpolitikon, não só animal social, mas animal que só pode isolar-se em sociedade. A produção do indivíduo isolado fora da sociedade [...] é uma coisa tão absurda como o desenvolvimento da linguagem sem indivíduos que vivam juntos e falem entre si".

6 "Por gramatização deve-se entender o processo que conduz a descrever e instrumentar uma língua na base de duas tecnologias, que são, ainda hoje, os pilares de nosso saber metalinguístico: a gramática e o dicionário" (AUROUX, 1992, p. 65).

7 "Em suma, interpretar, para o analista de discurso, não é atribuir sentidos, mas expor-se à opacidade do texto (ainda Pêcheux), ou, como tenho proposto (ORLANDI, 1987), é compreender, ou seja, explicitar o modo como um objeto simbólico produz sentidos, o que resulta em saber que o sentido sempre pode ser outro." (ORLANDI, 1996, p. 64).
} 
proposta didática com o seguinte trajeto: após estudos teóricos sobre o dicionário como objeto discursivo, fizemos um exercício na sala de aula utilizando algumas palavras para que os/as alunos/as mobilizassem sentidos e vivenciassem um gesto teórico-analítico de efeitos paradoxais de "familiaridade" e "estranhamento" com as palavras. Exercício que exigia problematizar 0 efeito de sentido e sua manifestaçãoenquantoefeito de evidência e, também, questionar sua produção em busca do caráter material do sentido ${ }^{8}$.

Em sala de aula, a partir da perspectiva dialógica de Freire $(1996)^{9}$, solicitamos à turma que citasse palavras que imediatamente viessem à sua mente, algo semelhante a dizeres em associação livre. Ou seja, depois de discutir a teoria, solicitamos à turma que apresentasse palavras aparentemente "soltas", para, em seguida, pensarmos sobre sua discursividade e concretude históricas. As palavras vieram com força em sua carga semântica e histórica. Foram elas: "educação", "política", "saúde", "segurança", "trabalho". E fomos compreendendo que, por meio das palavras aparentemente "soltas", ditas pelos/as graduandos/as e grafadas no quadro, em sala de aula, havia diversas discursividades ali em funcionamento; percursos de sentidos, filiações históricas que demarcavam as posições sujeitos e as diferentes interpretações sobre o real sócio-histórico. Tudo isso acontecia porque as condições materiais e ideológicas de produção num contexto de eleição assim o exigiam.

Tais escolhas das palavras, para quem conseguia questioná-las, já revelavam certa discursividade, traços de direcionamentos políticos, gestos de interpretação, marcas das condições de produção dos discursos. As palavras apresentavam-se também como uma via de fazer pensar nossa existência histórica e nossas relações com determinados sentidos, ou seja, evidência/familiaridade e, ao mesmo tempo, crítica/estranhamento. Diferentes sentidos brotavam naquelas palavras e que eram

\footnotetext{
${ }^{8}$ Sobre o caráter material do sentido, sugerimos a leitura do texto de SILVA SOBRINHO (2019), "O caráter material do sentido e as classes sociais: uma questão para a Análise do Discurso", no qual o autor enfatiza que o gesto de buscar o caráter material do sentido a partir dos estudos de Pêcheux poderá lançar luzes sobre o entendimento do caráter dialético da produção de sentidos e na constituição de sujeitos na processualidade histórica atual.

9 "A dialogicidade não nega a validade de momentos explicativos ou narrativos em que o professor expõe ou fala do objeto. O fundamental é que professor e alunos saibam que a postura deles, do professor e dos alunos, é dialógica, aberta, curiosa, indagadora e não apassivada, enquanto fala ou enquanto ouve. O que importa é que professor e alunos se assumam epistemologicamente curiosos." (FREIRE, 1996, p. 86).
} 
"sentidos" na pele e na alma não só dos estudantes, mas do professor que escreve este artigo. No debate/embate com esses sentidos, a forma-histórica do sujeito e a historicidade da interpretação foram se apresentando.

Sabemos que o discurso é um continuum ${ }^{10}$ e que as palavras ali evocadas apresentavam apenas recortes (fragmentos) dos diversos discursos dominantes e dominados em sua conformidade e/ou em sua resistência e que circulavam na formação social brasileira que clama, hoje, cada vez mais, por outras direções políticas e econômicas na sua história. As palavras ditas pelos/as estudantes eram recortes do dizível exterior e interior ao sujeito. Exterior, porque tais palavras preexistiam ao sujeito enquanto interdiscurso ${ }^{11}$, mas também interior, porque são interiorizadas no sujeito com suas diferentes discursividades e contraditórias inscrições ideológicas.

Tais palavras, na fluidez da língua, quando analisadas, apresentavam regularidades, ou seja, havia inscrições em determinadas formações discursivas ${ }^{12}$ que regiam o que se deveria ser dito e o que não poderia ser dito naquele momento histórico de eleições municipais. Com as palavras ali postas no quadro, já conseguíamos perceber outras possíveis formulações intradiscursivas, que remetidas ao processo discursivo, apresentavam sua relação conflituosa com as ideologias dominantes e dominadas, nas condições históricas que vivíamos naquele momento. Disputas de sentidos, conflitos entre sujeitos, forças em lutas e, sobretudo, desejos de mudanças e transformações sociais.

Assim, prosseguimos. Dessa primeira experiência/vivência didática surgiu a ideia apresentada pelo próprio alunado de formar grupos de estudantes da turma para repetirem essa relação de sentidos com outros grupos de sujeitos além dos muros da universidade, ou seja, questionar a produção de sentidos a partir

\footnotetext{
10 "Todo discurso nasce em outro (sua matéria-prima) e aponta para outro (seu futuro discursivo). Por isso, na realidade, não se trata nunca de um discurso, mas de um continuum. Fala-se de um estado de processo discursivo. Esse estado deve ser compreendido como resultado de processos discursivos sedimentados." (ORLANDI, 2000, p. 18).

${ }^{11}$ Entendemos interdiscurso como o já-dito, em outro lugar, em outro momento. Segundo Orlandi (1999, p. 31), "o interdiscurso disponibiliza dizeres que afetam o modo como o sujeito significa em uma situação discursiva dada".

${ }^{12} \mathrm{O}$ sentido não existe em si mesmo, mas é determinado pelas posições ideológicas no processo sócio-histórico. Podemos dizer que "a formação discursiva se define como aquilo que numa formação ideológica dada - ou seja, a partir de uma posição dada em uma conjuntura sócio-histórica dada determina o que pode e deve ser dito." (ORLANDI, 1999, p. 43).
} 
dosdizeres degrupos de amigos, de familiares, de lazer, de trabalho, da Igreja etc.A palavra "política" foi escolhida por unanimidade pela turma para ser levada para fora da universidade, num processo dialógico e investigativo sobre a produção de sentidos. Essa palavra seria utilizada na pesquisa para desenvolver uma determinada escuta, pois havia algo pulsando entre os/as estudantes que precisava ser exercitado, experienciado, vivenciado e, sobretudo, radicalmente compreendido. Havia, entre nós, uma postura curiosa e crítica a ser desenvolvida com a produção do conhecimento sobre a relação da língua com a sociedade, sobre a inscrição da língua na história e da história na língua.

Como dissemos, propusemos à turma que se formassem grupos de alunos/as para vivenciar outros sentidos (im)possíveis na conjuntura histórica determinada, visto que compreender os efeitos de sentidos exige investigar as condições de produção do discurso, já que a língua em seu funcionamento é constituída histórica e politicamente.

Nessa atividade em grupo, os/as estudantes do curso de Letras trataram de interpelar grupos de sujeitos fora do espaço da universidade com as seguintes perguntas: "qual o sentido da palavra "política" para você?", "o que é política?”, "o que você acha da política?".

Mesmo sendo uma pesquisa embrionária, um exercício de "sondagem",podemos afirmar que os/as estudantes realizaram uma pesquisa fora do campus universitário com certo rigor metodológico, pois já tínhamos refletido sobre a Análise do Discurso, sobre a produção e a historicidade dos efeitos de sentidos, e, especialmente, sobre a constituição e a posição ideológica dos sujeitos. Nessa perspectiva, compreendiam que ler não é decodificar, mas produzir sentidos a partir de posições-sujeito determinadas numa conjuntura histórica.

Além dessa reflexão teórica, os/as estudantes fizeram também estudos e pesquisas sobre a palavra "política", compreendendo a palavra em seu sentido dominante, ou seja, como ela se apresentaem dicionários, manifestando uma ordem que lineariza a dispersão de sentidose materializa os trajetos sociais, entrecruzando dizeres e silenciamentos ${ }^{13}$ nos quais o linguístico e o ideológico se entrelaçam,como podemos ver abaixo:

\footnotetext{
${ }^{13}$ Para Orlandi (2002), uma vez que as palavras são atravessadas de silêncio e produzem silêncio, o silêncio é condição do significar. Ainda segundo a autora: "há um modo de estar em silêncio que
} 


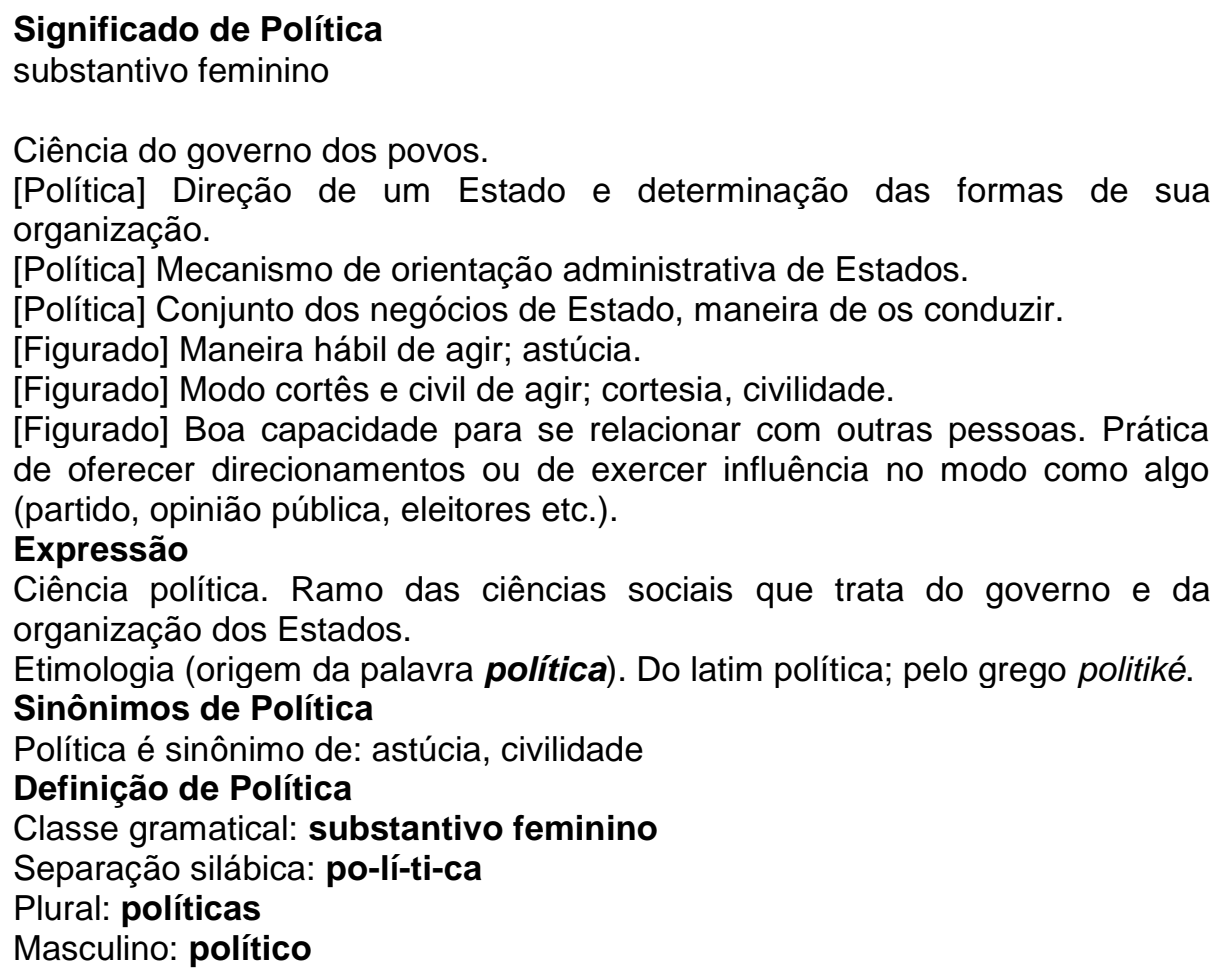

Fonte: Dicionário Online de Português

Embora tenhamos trazido o recorte do dicionário acima, não desenvolveremos uma reflexão detalhada sobre ele.Cabe-nos dizer que em toda palavra dicionarizada, apesar da aparência de estabilização de sentido, a formulação da palavraexpressaum movimento de paráfrase e polissemia, repetição e diferença, retomadas e substituições, enquanto processos inscritos nas relações sóciohistóricas. São dizeres possíveis em determinado momento histórico de uma dada sociedade. Inscrição da história na língua e vice-versa. Vale ressaltar ainda que, para a Análise do Discurso,mesmo utilizando dicionários, "a questão crucial é construir interpretações sem jamais neutralizá-las nem no 'não-importa-o-quê' de um discurso sobre o discurso, nem em um espaço lógico estabilizado com pretensão universal" (PÊCHEUX, 2011b, p. 294).

Ainda como atividade motivadora, uma aluna trouxe à sala de aula um poema de Bertolt Brecht para fornecer base crítica à discussão acerca da palavra "política". Era, a nosso ver, um gesto de leitura interpretação condizente com a prática do analista de discurso que articula um dizer com outros dizeres que atravessam o fio 
do discurso. Já-ditos em outros lugares, em outros momentos históricos, mas que fazem sentido na atualidade. Formulação que convoca àreflexão, que demonstra que a palavra não é a-histórica, pois o poema dialoga com os dizeres da atualidade na tensão com a memória discursiva ${ }^{14}$ em seus conflitos históricos e, também, faz os sujeitos manterem uma relação menos ingênua com a linguagem e com o político.

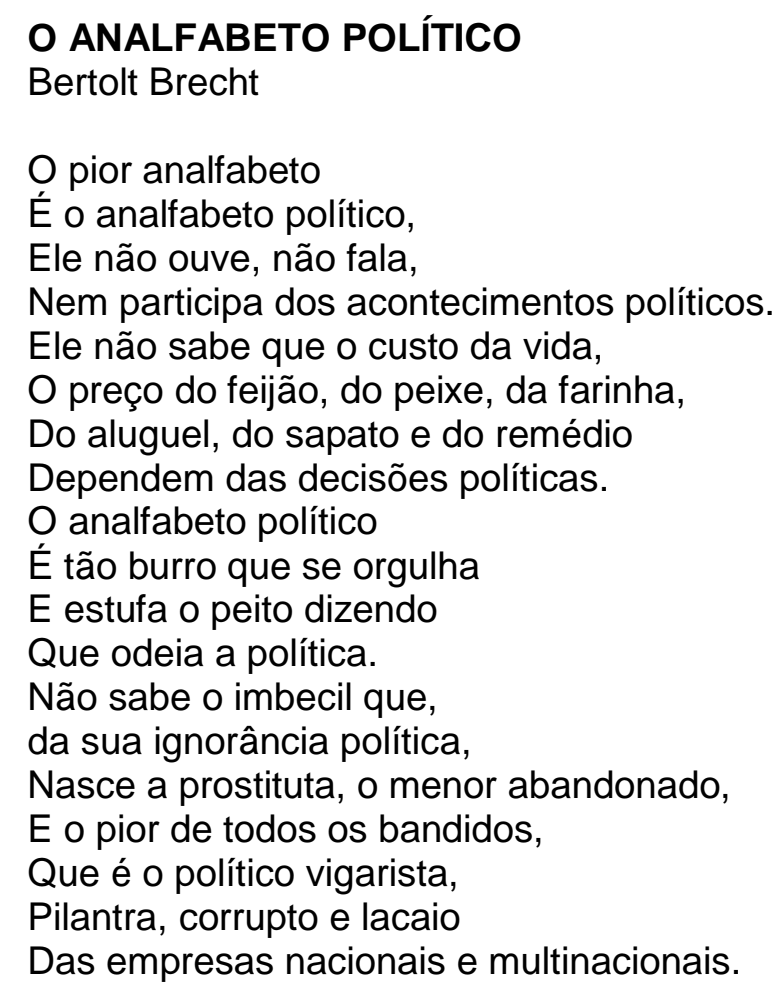

Sendo a língua capaz de poesia e política, após as reflexões desenvolvidas em sala de aula em torno dos efeitos dominantes e contra-hegemônicos da palavra "política", com base no dicionário e no poema de Brecht, a turma partiu ao campo para desenvolver sua pesquisa. Todo gesto fundamentava-se no que diz Pêcheux: "[...] não se trata de intervenções puramente técnicas: certa maneira de tratar o texto está inextricavelmente imbricada em uma certa maneira de fazer política" (2011a, p. 178).

Assim, os/as alunos/as escolheram os grupos de sujeitos a serem entrevistados e explicaram a atividade de pesquisa para obterem o consentimento

\footnotetext{
14 "Tocamos aqui um dos pontos de encontro com a questão da memória como estruturação de materialidade discursiva complexa, estendida em uma dialética da repetição e da regularização: a memória discursiva seria aquilo que, face a um texto que surge como acontecimento a ler, vem restabelecer os 'implícitos' (quer dizer, mais tecnicamente, os pré-construídos, elementos citados e relatados, discursos-transversos, etc.) de que sua leitura necessita: a condição do legível em relação ao próprio legível". (PÊCHEUX, 1999, p. 52).
} 
dos sujeitos. Os/as estudantes do curso de Letras fizeram entrevistas, aplicaram questionários, promoveram rodadas de conversas em ambiente descontraído, estabeleceram diálogo, souberam escutar e puderam dizer também algo sobre a palavra em questão. Utilizaram papel e caneta para escrever, gravaram em áudio, alguns também em vídeo.

O questionamento inicial consistia em saber,mediante a amostra dos dizeres dos sujeitos entrevistados, se era possível compreender os sentidos da palavra "política" em sua historicidade, ou seja, como esta palavra na relação da linguagem com a subjetividade afetavaos sujeitos em sua práxis histórica.

Os/as universitários/asem sua atividade de pesquisa se questionavam também se a palavra "política" produzia o mesmo sentido para todas aspessoas entrevistadas ou, pelo contrário, se havia alguma nuança de sentido ou aspectos contraditórios.Eles/as estavam construindo um saber sobre a língua, sobre a política, sobre os sujeitos e sobre a história e chegaram aos seguintes resultados das entrevistas, que apresentaremos, sucintamente, no quadro abaixo:

Grupo 1:entrevistou pessoas na faixa de 16 anos e também nas faixas de 50 e 60 anos.

Recortes dasmaterialidades discursivas:

Pessoas com idade entre 50 e 60 anos

"A política é assim, começa pelos candidatos e é bom para uns e ruim para outros, e é ainda pior para os nordestinos".

"A política é quando as pessoas se candidatam para colocar os ricos pra frente e os pobres sempre ficam para trás".

Pessoas com idade de 16 anos:

"A política é quando as pessoas confiam em outra para cuidar de seus bens, como saúde e educação, mas muitas das vezes eles acabam sendo corruptos e decepcionando a quem confiou".

"É algo que se refere ao futuro de uma nação e é onde o cidadão pode falar ou se expressar em relação a quem ele vai dar um voto de confiança na administração de quem ele escolhe".
Grupo 2: entrevistou estudantes com idade entre 16 e 18 anos de uma escola municipal.

Recortes das materialidades discursivas:

"Política é uma coisa que todos nós vamos um dia dar um emprego para as outras pessoas, pois isso é política, bota uma pessoa como prefeito etc."

"Eu só queria que esses políticos parassem de roubar. Eu acho que não só eu como todos juntos poderíamos mudar tudo isto, pois têm muitos políticos comprando votos por aí..." 
Grupo 3: entrevistou jovens que participam de um grupo de oração de religião católica.

Recortes das materialidades discursivas:

"Meio pelo qual os candidatos chegam ao poder."

"Na política só tem corrupto."

"A política deve ser exercida de maneira honesta e não com compra de votos".

"Muitos roubam o dinheiro que é para investir em saúde, educação de qualidade".

No Brasil, atualmente, a política está uma bagunça."

Para que o país seja representado com dignidade, na política, devem existir pessoas honestas".

Grupo 5: entrevistou pessoas entre 30 e 63 anos de um sindicato.

Recortes das materialidades discursivas:

"Uma palhaçada, que só beneficia os próprios políticos."

"Política é saber viver em sociedade, é a forma que o homem encontra para defender os interesses da sociedade e, ultimamente, os interesses dele mesmo."

"Política era uma coisa diferente da realidade, daquilo que algumas pessoas conceituam, que são os políticos, os responsáveis pelo que há de bom ou ruim em uma sociedade ou nação, porque política é a arte de bem viver em sociedade."

"Política é você ter um ideal na vida e lutar por ele."
Grupo 4: entrevistou professores da rede municipal de ensino.

Recortes das materialidades discursivas:

"É uma oportunidade de escolher novos gestores comprometidos com as necessidades básicas do município".

"A política só tem corrupto, político ladrão que rouba os direitos da população em benefício próprio, pois eles deixam de aplicar os investimentos em sua totalidade nas necessidades básicas do município e compram casas, propriedades e automóveis para ostentarem na sociedade."

"Não acredito em plano de governo porque eles não cumprem o que prometem".

Grupo 6: entrevistou estudantes do Ensino Médio, com idade entre 16 a 19 anos.

\section{Recortes materialidades discursivas:}

"Política hoje é politicagem, corrupção"

Grupo 7: entrevistou alunos/as de 16 a 21 anos do $3^{\circ}$ ano do Ensino Médio de uma escola estadual.

Recortes das materialidades discursivas:

"A política são pessoas que irão nos representar."

Nos recortes das materialidades discursivas acima, podemos observar os traços da interpretação sobre a palavra "política". Não estamos aqui tratando de sentidos produzidos na palavra em si e por si mesma,pois consideramos que a língua tem sua relativa autonomia, apesar de sofrer tensões diante da 
discursividade ${ }^{15}$. Assim, nesse espaço do dizer, estamos tratando de historicidade e de como a palavra "política" é significada no/pelo discurso em condições de produção determinadas.Como diz Pêcheux:

\begin{abstract}
E é neste ponto que se encontra a questão das disciplinas de interpretação: é porque há o outro nas sociedades e na história, correspondente a esse outro próprio ao linguajeiro discursivo, que aí pode haver ligação, identificação ou transferência, isto é, existência de uma relação abrindo a possibilidade de interpretar. E é porque há essa ligação que as filiações históricas podem-se organizar em memórias, e as relações sociais em redes de significantes. (PÊCHEUX, 2002, p. 54)
\end{abstract}

Em nossa análise, junto com os/as alunos/as, compreendemos que a palavra "política" remete na atualidade, em suas filiações de sentidos e práticas materiais e ideológicas, às noções de "corrupção" e "roubo". Pudemos perceber isso no quadro acima: "na política só tem corrupto" /"política hoje é politicagem, corrupção"/"política só tem corrupto, político ladrão que rouba os direitos da população"/“muitos roubam o dinheiro que é para investir em saúde, educação de qualidade".

Interessante notar também que os dizeres iniciam-se estabelecendo relações de sentido entre a palavra "política" com "escolha", "oportunidade de mudança", "voto de confiança", mas logo esses sentidos derivam para "decepção", o que faz o sujeito expressar seu desejo: "queria que parassem de roubar", e que"a política deve ser exercida de maneira honesta". Esses desejos materializados no discurso estão relacionados com a necessidade e urgência de transformação social, e assim demarcam processos de sentidos diferenciados.

Os/as entrevistados/astambém compreendem que política é "viver em sociedade"|"a arte de bem viver em sociedade". Vemos aí uma compreensão da política de modo amplo, que escapa dos sentidos de corrupção e se amplia para o viver em sociedade politicamente. Mas, de maneira geral, domina o sentido de desconfiança em relação à política: "não acredito em plano de governo porque eles não cumprem o que prometeram".

Sabemos que quando o sujeito diz alguma coisa ele significa o mundo e a si mesmo. Não há como fugir da interpretação (ORLANDI, 1996). Essa forma histórica do sujeitoeleitor/a traz sentidos que se sedimentam nos conflitos

15 "[...] o sistema da língua é, de fato, o mesmo [...]. Entretanto, não se pode concluir, a partir disso, que esses diversos personagens tenham o mesmo discurso: a língua se apresenta, assim, como a base comum de processos discursivos diferenciados." (PÊCHEUX, 1997, p. 91). 
socioeconômicos,tais como: política = eleição; política $=$ corrupção; política $=$ troca de favores; política = exercício da cidadania. Usamosaqui o sinal de igualdade (=) como produção de sentidos que se sedimenta contraditoriamente nas relações históricas. Não podemos deixar de explicitar: conflitos de sentidos, relações de forças, divisão de sujeitos, estabilização e deslocamentos de palavras e enunciados, retomadas/esquecimentos e silenciamentosde dizeres, estão em funcionamento nas redes de filiações das posições ideológicas dos sujeitos na práxis sócio-histórica.

Nas materialidades acima, podemos vislumbrar como os/as entrevistados/as assumem determinadas interpretações nas práticas históricas, visto que tais associações (des)velam, em sua inter-relação dialética, como os sujeitos e os sentidos de "política" vão se constituindo na história, pois são traços da discursividade de como os sentidos são administrados, retomados e se movimentam nos jogos de forças e conflitos sociais.

Apesar da particularidade da história de cada entrevistado/a, para a Análise do Discurso os sujeitos não são donos de seu dizer, porquanto estão inscritos, de modo contraditório, nas discursividades das relações sociais determinadas historicamente. Assim, as palavras que foram citadas pelos sujeitos entrevistados (política = eleição; política = corrupção; política = troca de favores; política = exercício da cidadania), em seu caráter material, manifestam as contraditórias relações de produção na sociedade capitalista,

É importante ressaltar que, em nossa análise, foi possível compreender que os/as estudantes do curso de Letras também se posicionaram como pesquisadores/as interessados/as em mobilizar os sentidos do que seja "política". Diante dos gestos de interpretação praticados por eles/as sobre os dizeres dos/as entrevistados/as, é possível dizer que no discurso que pretendiam definir, explicar/compreender o que é "política", há uma inscrição dos sujeitos na forma histórica do/a eleitor/a brasileiro/a na atualidade.

Com esse exercício da vivência do questionamento da palavra "política", e levando em consideração que a inscrição do sujeito no discurso já é uma prática política, os/as estudantes, em seu exercício de leitura e interpretação, em sua vivência/experiência didática e política, chegaram às seguintes conclusões: 
das práticas desfavoráveisda política, com corrupção e má gestão. (Conclusões do Grupo de alunos/as G1).

É perceptível o olhar curioso que eles [os sujeitos entrevistados] demonstraram sobre os sentidos da palavra política. Vimos que os depoimentos mostram entendimento crítico do meio político e necessidades democráticas. E também enfatiza o desejo de serem ouvidos e de que nasça uma política diferente, um novo pensamento, um olhar que transformeo conhecimento e a prática daquilo que é a política. (Conclusões do Grupo de alunos/as G4).

Com as análises compreendemos cada vez mais que a política não pode ser compreendida como algo em si mesmo, sem história. Há uma relação entre língua e história, e por isso ela tem contradições da vida de cada um. (Conclusões do Grupo de alunos/as G5).

Interessa dizer que os/as alunos/as do curso de Letras, enquanto pesquisadores/as e cidadãos/ãs, ao articularem o dizer e suas condições de produção, chegaram a conclusões relevantes sobre a produção de sentidos na leitura da palavra "política". Cabe destacar que eles tomaram também posição crítica em relação à palavra; isso significa que "tomar a palavra é um ato social com todas as suas implicações: conflitos, reconhecimentos, relações de poder, constituição de identidades etc." (ORLANDI, 2000, p. 17). Ou seja, deram passos na compreensão da realidade, na tentativa de desmontar os sentidos dominantes. Potencialmente, puderam captar as contradições do movimento de sentidos, inscrevendo-se como sujeitos críticos que entendem fazer parte de um processo histórico.

Assim, os/as estudantes também compreenderam que o "sentido da palavra política na vida das pessoas muda com o passar do tempo"; movimentaram a interpretação, já que há uma crença inicial na "cidadania plena" e "depois, o cenário é de desilusão", devido à "corrupção". Esse processo de significação da "política" como "corrupção" é histórico, e revela a "desilusão" das práticas políticas corrompidas pela lógica do sistema capitalista no estado burguês.De acordo com Boito (2017), "a corrupção é uma noção ideológica do Estado de tipo capitalista: a ideologia apresenta tal estado como se fosse uma instituição pública, quando ele é, de fato, uma instituição de classe" (BOITO, 2017, p. 18).

Em nossa análise, consideramos que os/as estudantes, utilizando o dispositivo teórico e analítico da Análise do Discurso, também compreenderam e interagiram dizendo que os/as entrevistados/as tinham um "olhar curioso" sobre o "entendimento do meio político e democrático". Por fim, destacaram que "a política não pode ser compreendida como algo em si mesmo, sem história", que há o "desejo de serem ouvidos e de que nasça uma política diferente, um novo pensamento, um olhar que transforme o conhecimento e a prática daquilo que é a política.". 
Desse modo, os/as estudantes, em suas práticas de pesquisa com a linguagem e a produção de sentidos na história, restabeleceram os não-ditos, chegaram aos implícitos, depararam-se com os silenciamentose, sobretudo, souberam reconhecer as marcas históricas das condições de produção do discurso. Assim, mobilizaram a interpretação, sabendo que os sentidos estão margeados por dizeres dominantes;estranharam as evidências, pensaram em outros sentidos (im)possíveisem nossa conjuntura histórica e expressaram desejos de que os sentidos pudessem ser outros.

Portanto, os/as estudantes tomaram posição ante as questões políticas e à palavra "política" e seus efeitos de evidência. Desenvolveram uma escuta discursiva. Tomaram a palavra e estabeleceram possibilidades enunciativas de criticar o efeito ideológico da transparência da linguagem e seus dizeres dominantes.

\section{CONSIDERAÇÕES FINAIS: A LEITURA POLÍTICA E A POLÍTICA DA LEITURA}

A leitura, portanto, não é uma questão de tudo ou nada, é uma questão de natureza, de condições, de modos de relação, de trabalho, de produção de sentidos, em uma palavra: de historicidade. (ORLANDI, 2000, p. 9)

Estar no mundo sem fazer história, sem por ela ser feito, sem fazer cultura, sem 'tratar' sua própria presença no mundo, sem sonhar, sem cantar, sem musicar, sem pintar, sem cuidar da terra, das águas, sem usar as mãos, sem esculpir, sem filosofar, sem pontos de vista sobre o mundo, sem fazer ciência, ou teologia, sem assombro em face do mistério, sem aprender, sem ensinar, sem ideias de formação, sem politizar, não é possível. (FREIRE, 1996, p. 58).

Em nossas considerações finais, é preciso dizer que o exercício de reflexão teórica e política no ensino básico, na universidade e na vida cotidiana deve ser constante,principalmente diante da conjuntura que vivenciamos hoje, com o avanço e a vitória do conservadorismo e do neoliberalismo, ea dominância das interpretações reacionárias da política. É nessa direção que a leitura política da palavra toca na questão dos efeitos de sentidos no discurso e suas condições históricas, materiais e ideológicas de produção. Fazer isso é um gesto de leitura e interpretação fecundamente crítico.

A nosso ver, o sujeito, afetado pela ideologia e pelo inconsciente, tem sua particularidade histórica. Há traços dos sentidos que se sedimentam e são 
materializados em seus dizeres sobre a palavra "política" (que não é transparente) na relação entre língua, história e subjetividade. É preciso dizer que nas condições históricas que vivenciamos, para que haja uma leitura da palavra que não se satisfaça com a evidência de sentido, é necessário assumir sempre uma postura que vá contra as práticas desumanizadora da formação social capitalista e busque encontrar alternativas de superação.

Desconfiar das evidências da palavra "política" nos faz também desnaturalizar as relações de sentidos (política=corrupção) e desejar outras formas de sociabilidade em que a política não se incline ao ataque à democracia e à prática da“corrupção", reduzindo-se à"enganação" e ao "roubo", que são ditames da lógica capitalista. Há, pois, a necessidade urgente de, nas práticas de ensino, ressaltar acrítica às ideias dominantes como uma forma de resistência. Segundo Silva Sobrinho:

\begin{abstract}
A nosso ver, fazer AD é sempre uma prática desafiadora na conjuntura histórica de reprodução/transformação das relações de produção, ou seja, o fazer ciência e política é, ao mesmo tempo, parte constitutiva das relações antagônicas existentes entre capital e trabalho. Portanto, nossa prática (confortável e/ou desconfortavelmente) tem conexões com determinadas classes, porquanto não pode estar isolada da práxis sócio-histórica. (SILVA SOBRINHO, 2014, p. 41).
\end{abstract}

Gostaria de terminar este texto lembrando que no livro "Pedagogia da Autonomia", Paulo Freire nos convoca a criticar "a malvadez neoliberal, o cinismo de sua ideologia fatalista e sua recusa inflexível ao sonho e à utopia" (FREIRE, 1996, p. 14). Por sua vez, a Análise do Discurso nos põe a questão de que os sentidos são múltiplos e têm suas histórias junto com os sujeitos em determinadas posições e condições de produção,e como diz Michel Pêcheux, "em face das interpretações sem margens nas quais o intérprete se coloca como um ponto absoluto, sem outro nem real, trata-se aí, para mim, de uma questão de ética e política: uma questão de responsabilidade" (PÊCHEUX, 2002, p. 57).

Assim, se os sentidos podem ser sempre outros, que lutemos por outros sentidos, outras leituras políticas e que estasoutras interpretaçõesnos levem anovos patamares emancipatórios de humanidade. 


\section{REFERÊNCIAS}

ARISTÓTELES. Política. São Paulo: Martin Claret, 2004.

AUROUX, S. A revolução tecnológica da gramatização. Campinas: Editora da Unicamp, 1992.

BOITO, A. A corrupção como ideologia. Revista Crítica Marxista, Campinas, n. 44, 2017,p. 9-19.

FREIRE, P. Pedagogia da autonomia: saberes necessários à prática educativa. São Paulo: Paz e Terra, 1996.

HENRY, P. Os fundamentos teóricos da 'Análise Automática do Discurso' de Michel Pêcheux. In: GADET, F.\& HAK, T. (org.). Por uma análise automática do discurso:uma introdução à obra de Michel Pêcheux. Campinas: Editora da Unicamp, 1997.p. 13-38. Originalmente publicado em 1969.

LUKÁCS, G. Para uma ontologia do ser social II. São Paulo: Boitempo, 2013.

MARX, K. O Capital.Livro I. São Paulo: Nova Cultural, 1985.

MARX, K. Para a crítica da economia política.São Paulo: Nova Cultural, 1996.

MARX, K. Teses sobre Feuerbach. In: MARX, K.; ENGELS, F. A ideologia Alemã.São Paulo: Martins Fontes, 1998.p. 99-103.

MÉSZÁROS, I. Educação para além do capital. São Paulo: Boitempo, 2005.

ORLANDI, E. A leitura e os leitores. Campinas: Pontes, 1998.

ORLANDI, E. Análise de discurso: princípios e procedimentos. Campinas: Pontes, 1999.

ORLANDI, E. As formas do silêncio no movimento dos sentidos.Campinas:

Editora da Unicamp, 2002.

ORLANDI, E. Discurso e leitura. São Paulo: Cortez; Campinas: Ed. da Unicamp, 2000.

ORLANDI, E. Discurso e texto: formulação e circulação dos sentidos. Campinas: Pontes, 2001.

ORLANDI, E. Interpretação: Autoria, leitura e efeitos do trabalho simbólico.

Petrópolis: Vozes, 1996.

PÊCHEUX, M.; GADET, F. A língua inatingível. Campinas: Pontes, 2004.

PÊCHEUX, M. O discurso: estrutura ou acontecimento. Campinas: Pontes, 2002. 
PÊCHEUX, M. Papel da memória. In: ACHARD, P. et al. (org.).Papel daMemória. Campinas: Pontes, 1999.p. 49-57.

PÊCHEUX, M. Remontemos de Foucault a Spinoza. In: BARONAS, R. (org.). Análise de Discurso:apontamentos para uma história da noção-conceito de formação discursiva. São Carlos: Pedro \& João Editores, 2011a.p. 177-192.

PÊCHEUX, M. Semântica e Discurso: uma crítica à afirmação do óbvio. Campinas: Ed. da Unicamp, 1997.

PÊCHEUX, M. Sobre os contextos epistemológicos da Análise de Discurso. In: ORLANDI, E. Análise de Discurso Michel Pêcheux:textos selecionados. Campinas: Pontes, 2011b. p. 283-294.

SILVA SOBRINHO, H. O analista de discurso e a práxis sócio-histórica: um gesto de interpretação materialista e dialético. Revista Conexão Letras, Porto Alegre, v. 9, n. 12, p. 37-50, 2014.

SILVA SOBRINHO, H. O caráter material do sentido e as classes sociais: uma questão para a Análise do Discurso. Revista Polifonia, Cuiabá, v. 26, n. 43, p. 130150., jul.-set. 2019.

\section{Sobre o autor}

\section{Helson Flávio da Silva Sobrinho}

Helson Flávio da Silva Sobrinho é professor e pesquisador da Universidade Federal de Alagoas (UFAL), atua na graduação em Letras, no Programa de Pós-graduação em Linguística e Literatura (PPGLL) e no Profletras. É bolsista Produtividade em Pesquisa do CNPq. Sociólogo e doutor em Linguística na área de Análise do Discurso (AD). É pós-doutor pelo IEL-Unicamp. Desenvolve estudos sobre Discurso, Sujeito, História e Ideologia. É vice-líder do grupo de pesquisa: Discurso e Ontologia (Gedon). É autor do Livro "Discurso, Velhice e Classes Sociais", possui também publicações de capítulos de livros e artigos em diversas revistas especializadas na área de Linguística e Análise do Discurso. 